\title{
Sensitivity Improvement of Ammonia Determination Based on Flow-Injection Indophenol Spectrophotometry with Manganese(II) Ion as a Catalyst and Analysis of Exhaust Gas of Thermal Power Plant
}

\author{
Tomonori Tsubor, ${ }^{* \dagger}$ Yoshio Hirano, ${ }^{*}$ Yoshinori Shibata, $* *$ and Shoji Motomizu*** \\ *The Chugoku Electric Power Co., Inc. Technical Research Center, \\ 3-9-1, Kagamiyama, Higashi-Hiroshima 739-0046, Japan \\ **Chuden Kankyo Technos Co., Ltd., 3-9-1, Kagamiyama, Higashi-Hiroshima 739-0046, Japan \\ ***Department of Chemistry, Faculty of Science, Okayama University, \\ 3-1-1, Tsushima-naka, Okayama 700-8530, Japan
}

\begin{abstract}
The sensitivity improvement of a flow-injection spectrophotometric method for the determination of ammonia was examined based on an indophenol blue coloration reaction with salicylate and hypochlorite in the presence of manganese(II) as a reaction promotion catalyst. The optimal conditions for achieving higher sensitivity of ammonia determination were examined using a three-line flow system. The limit of detection corresponding to a signal-to-noise ratio $(S / N)$ of 3 was $0.005 \mathrm{mg} \mathrm{l}^{-1}$ (三5 ppb) of $\mathrm{NH}_{4}{ }^{+}$. A calibration graph was linear in the range from $5 \mathrm{ppb}$ to $1000 \mathrm{ppb}$ of ammonium ion. The relative standard deviations $(n=9)$ for $50 \mathrm{ppb}$ and $100 \mathrm{ppb}$ of ammonium ion were $6.4 \%$ and $2.2 \%$, respectively. The proposed method was applied to the determination of ammonia in the exhaust gas of a thermal power plant. Prior to the FIA determination, ammonia in the exhaust gas was absorbed into a boric acid solution; the absorption solution was then analyzed by the proposed FIA.
\end{abstract}

(Received June 12, 2002; Accepted August 22, 2002)

\section{Introduction}

Nitrogen oxides $\left(\mathrm{NO}_{\mathrm{x}}\right)$ can be formed by a thermal power plant boiler when it works under the combustion of fuel; ammonia is added to the exhaust gas to remove $\mathrm{NO}_{\mathrm{x}}$, which reacts with ammonia to give nitrogen and water in a denitrification system. Though the efficiency of the denitrification system can be improved by increasing the amount of ammonia added to the exhaust gas, residual ammonia, which is not used for the denitrification reaction, can leak out of the denitrification system and become the causes of various troubles, including atmospheric pollution.

The determination of ammonia in exhaust gas has been carried out by a method consisting of such procedures as sampling the exhaust gas, the dissolution of ammonia in the exhaust gas into an absorption solution (boric acid), and the determination of ammonium ion in the absorption solution by a batchwise absorptiometry. Usually, these procedures have been carried out manually; therefore, the method used to determine ammonia is very tedious and time-consuming. ${ }^{1}$ Furthermore, to construct an automatic feed-back system for adding adequate amounts of ammonia to exhaust gas, a rapid and simple determination system for ammonia is now urgently required. In order to automate the on-site determination of ammonia in the absorption solution, a flow injection analysis (FIA) was

$\dagger$ To whom correspondence should be addressed.

E-mail: 595184@pnet.energia.co.jp investigated in this work.

Several methods for the determination of ammonia by FIA have been proposed so far; some of the typical representatives are based on a spectrophotometric measurement with Nessler's reagent and phenol-hypochlorite reagents. ${ }^{2-6}$ The reactions with phenol-hypochlorite reagents show a relatively high sensitivity and selectivity for ammonia determination. Of the phenolhypochlorite reagents, a salicylic acid-hypochlorite reagent is most promising with respect to the chemical stability of the reagent used and the sensitivity for ammonium ion. As an automated system for the rapid and simple determination of ammonium ion, a spectrophotometric method coupled with FIA seems to be the best choice of the flow-based analysis methods used these days. A spectrophotometric FIA using sodium salicylate was applied to the determination of ammonia in the exhaust gas of a thermal power plant. ${ }^{6}$ In a method with salicylic acid and hypochlorite, ${ }^{4-6}$ nitroprusside has been used as a catalyst. The nitroprusside is a very useful reagent for a sensitivity enhancement of ammonia determination. However, it is a toxic substance, and should be replaced by a non-toxic or less-toxic substance.

In this work, some metal ions were examined as a catalyst, and the concentrations of the reagents used for the ammonia coloration reaction, reaction conditions and flow conditions were examined in detail for improving the sensitivity of ammonia determination without using nitroprusside. The established FIA method was found to be applicable to the exhaust gas of a thermal power plant. 


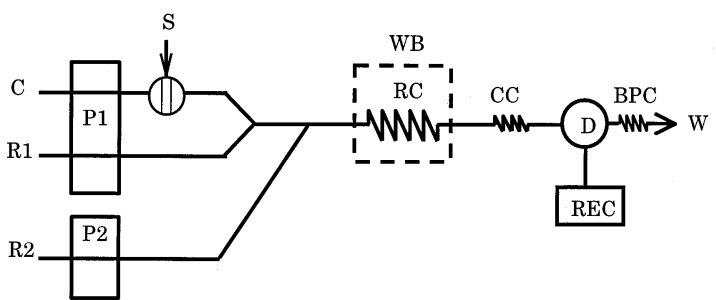

Fig. 1 FIA system for ammonia determination based on an indophenol blue method. C, carrier (boric acid aqueous solution); R1, reagent solution I (sodium salicylate, Mn(II), potassium sodium tartrate and sodium hydroxide); R2, reagent solution II (sodium hypochlorite and sodium hydroxide); P1, pump $\left(0.5 \mathrm{ml} \mathrm{min}^{-1}\right)$; $\mathrm{P} 2$, pump $\left(0.2 \mathrm{ml} \mathrm{min}^{-1}\right) ; \mathrm{S}$, sample $(0.5 \mathrm{~mm}$ i.d. $\times 1.5 \mathrm{~m}, 300 \mu \mathrm{l}) ; \mathrm{RC}$, reaction coil $(1.0 \mathrm{~mm}$ i.d. $\times 20 \mathrm{~m})$; WB, temperature-controlled bath; CC, cooling coil $(0.5 \mathrm{~mm}$ i.d. $\times 1 \mathrm{~m})$; D, detector $(665 \mathrm{~nm})$; REC, recorder; BPC, back-pressure coil $(0.25 \mathrm{~mm}$ i.d. $\times 1 \mathrm{~m})$; $\mathrm{W}$, waste.

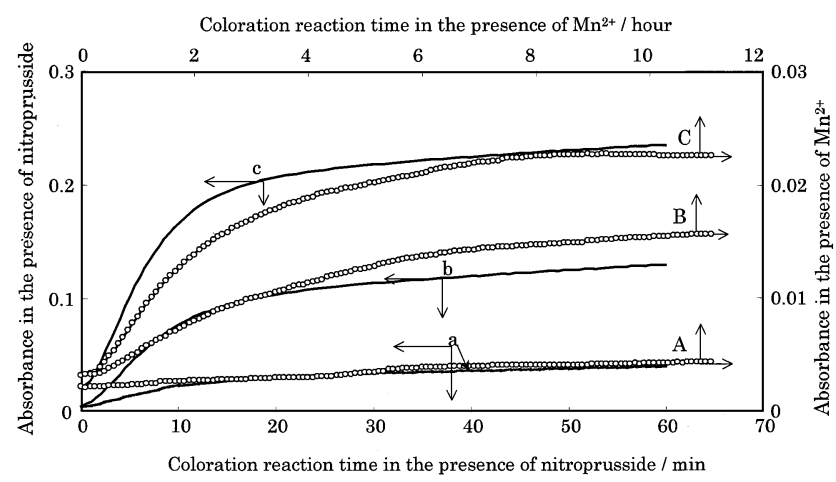

Fig. 2 Comparison of the coloration reaction time of $\mathrm{Mn}^{2+}$ with nitroprusside used as an acceleration catalyst. (A), (B) and (C), $\mathrm{Mn}^{2+}$; (a), (b) and (c), nitroprusside. $\mathrm{NH}_{4}{ }^{+}\left(\mathrm{mg} \mathrm{l}^{-1}\right)$ : (A) and (a) 0 , (B) and (b) $0.5,(\mathrm{C})$ and (c) 1.0 .

\section{Experimental}

Apparatus

A flow diagram for the determination of ammonium ion is shown in Fig. 1. The FIA system was mainly composed of a Hitachi FIA system (Model K-1000), a Hitachi plunger pump (Model L-6320), a Hitachi spectrophotometric detector (Model L-4200; optical path length, $10 \mathrm{~mm}$ of the flow cell; capacity, $17.7 \mu \mathrm{l}$; measurement wavelength, $665 \mathrm{~nm}$ ), and a GL Sciences data-processing software (Vstation).

\section{Reagents}

All of the solutions used were prepared using highly pure water of $18.3 \mathrm{M} \Omega \mathrm{cm}^{-1}$, which was prepared with a Milli Q system (Millipore Milli-Q SP TOC); the chemicals used were of analytical reagent grade.

Reagent solutions I and II. Reagent solution I was prepared by dissolving sodium salicylate, potassium sodium tartrate, and manganese sulfate in water. Reagent solution II was prepared by dissolving sodium hypochlorite in a sodium hydroxide solution $(0.5 \mathrm{M})$ to give a $0.2 \%$ (active chlorine) solution.

Standard ammonium ion solution. A stock solution containing $100 \mathrm{mg} \mathrm{l}^{-1} \mathrm{NH}_{4}{ }^{+}$was prepared by dissolving $0.297 \mathrm{~g}$ of ammonium chloride in 11 of highly pure water. Working solutions were prepared daily by diluting a stock solution of ammonium chloride accurately.
Table 1 Effect of metal ions as a catalyst for the determination of ammonia

\begin{tabular}{lcc}
\hline Metal ion & Concentration/M & Absorbance \\
\hline $\mathrm{Mn}^{2+}$ & $2.5 \times 10^{-3}$ & $-^{\mathrm{a}}$ \\
& $1.0 \times 10^{-4}$ & $-^{\mathrm{a}}$ \\
& $5.0 \times 10^{-5}$ & 0.0017 \\
& $2.5 \times 10^{-5}$ & 0.0017 \\
& $2.0 \times 10^{-5}$ & 0.0017 \\
$\mathrm{Co}^{2+}$ & 0 & 0.0001 \\
$\mathrm{Cu}^{2+}$ & $2.5 \times 10^{-3}$ & 0.0010 \\
$\mathrm{Fe}^{2+}$ & $2.5 \times 10^{-3}$ & 0.0006 \\
$\mathrm{Fe}^{3+}$ & $2.5 \times 10^{-3}$ & 0.0003 \\
$\mathrm{Fe}(\mathrm{CN})_{6}{ }_{6}-$ & $2.5 \times 10^{-3}$ & 0.0013 \\
$\mathrm{Fe}(\mathrm{CN})_{6}{ }^{4-}$ & $2.5 \times 10^{-3}$ & 0.0011 \\
\hline
\end{tabular}

a. Precipitation of manganese hydroxide occurred.

Concentration of $\mathrm{NH}_{4}{ }^{+}: 0.5 \mathrm{mg} \mathrm{l}^{-1}$. Reaction temperature was $80^{\circ} \mathrm{C}$, and the reaction tubing was $0.5 \mathrm{~mm}$ i.d. $\times 6 \mathrm{~m}$. Absorbances show the ones corresponding to peak height.

\section{Results and Discussion}

Investigation of catalysts for a sensitivity improvement of ammonia detection

Sodium nitroprusside acts as a catalyst for the formation of indophenol derivatives. However, sodium nitroprusside is known to be toxic, and a special treatment for experimental waste is necessary. In this work, other metal ions were examined to replace the nitroprusside. Manganese and other metals or metal complex ions $\left\{\mathrm{Co}^{2+}, \mathrm{Cu}^{2+}, \mathrm{Fe}^{2+}, \mathrm{Fe}^{3+}, \mathrm{Fe}(\mathrm{CN})_{6}{ }^{3+}\right.$ and $\mathrm{Fe}(\mathrm{CN})_{6}{ }^{4+}$ \} were examined; each metal or metal complex ion was added to reagent solution I in place of sodium nitroprusside. As shown in Table 1, of the metals or metal complex ions, $\mathrm{Mn}^{2+}$ was found to show the largest accelerating effect.

In order to compare the efficiency of catalysts with each other, the behavior of the color development was examined using nitroprusside and $\mathrm{Mn}^{2+}$ as a catalyst by a batchwise method. The obtained results are shown in Fig. 2. The absorbances with nitroprusside became almost identical within $30 \mathrm{~min}$, while in the case of $\mathrm{Mn}^{2+}$ about $8 \mathrm{~h}$ was required to obtain identical absorbances, which was about one tenth of the nitroprusside method. These results indicate that $\mathrm{Mn}^{2+}$ was less effective as a catalyst than nitroprusside in batchwise absorptiometry. To improve the sensitivity in the $\mathrm{Mn}^{2+}$ method, some other conditions for reaction acceleration must be examined in the FIA measurement. In the FIA measurement, various kinds of experimental parameters, such as reagent concentrations, reaction temperature and flow conditions, were re-examined to improve the sensitivity in the ammonium determination with $\mathrm{Mn}^{2+}$ used as a catalyst.

The effect of the concentrations of manganese sulfate in reagent solution I on the peak height was examined in detail by varying the concentration of $\mathrm{Mn}^{2+}$ from 0 to $2.5 \times 10^{-3} \mathrm{M}$. The peak height was increased with an increase of the $\mathrm{Mn}^{2+}$ concentrations; the accelerating effect was almost identical at concentrations from $2 \times 10^{-5} \mathrm{M}$ to $5 \times 10^{-5} \mathrm{M}$, and at $\mathrm{Mn}^{2+}$ concentrations of more than or equal to $1 \times 10^{-4} \mathrm{M}$, the PTFE tube was sometimes blocked by the deposition of manganese hydroxide. Therefore, $2.5 \times 10^{-5} \mathrm{M}$ of $\mathrm{Mn}^{2+}$ was adopted in further experiments.

Effect of the reagent concentrations on a sensitivity improvement of ammonia detection

The effect of the concentrations of sodium salicylate in 


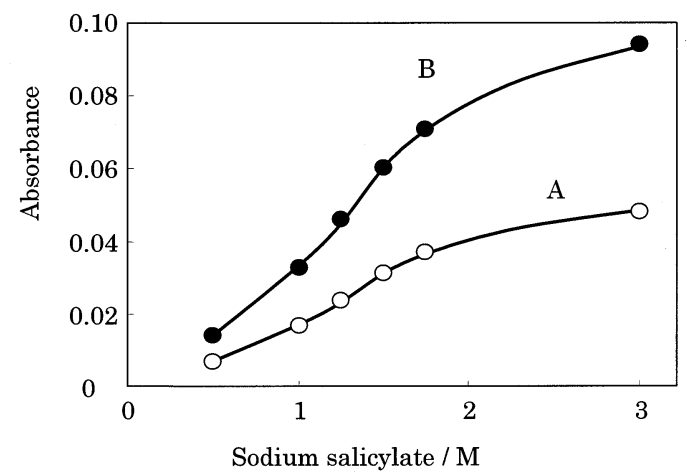

Fig. 3 Effect of the concentrations of sodium salicylate on the absorbance corresponding to the peak height. $\mathrm{NH}_{4}{ }^{+}$(mg l-1 ${ }^{-1}$ : (A) 5, (B) 10 .

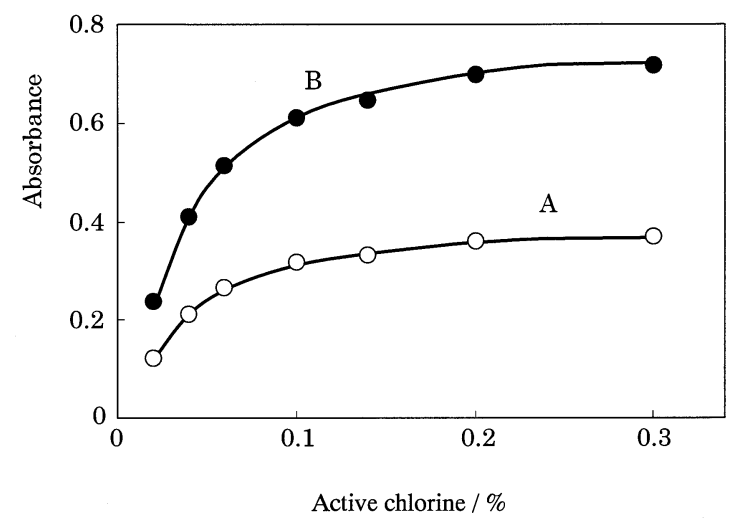

Fig. 4 Effect of the concentrations of sodium hypochlorite on the absorbance corresponding to the peak height. $\mathrm{NH}_{4}^{+}\left(\mathrm{mg} \mathrm{l}^{-1}\right)$ : (A) 5 , (B) 10 .

reagent solution I on the peak height was examined by varying them from $0.5 \mathrm{M}$ to $3 \mathrm{M}$; the obtained results are shown in Fig. 3. The peak height increased with increasing the concentration of sodium salicylate. In the concentration ranges above $3 \mathrm{M}$, it was very difficult to dissolve sodium salicylate into water. In further experiments, $1.75 \mathrm{M}$ was adopted because the difference in the absorbance between $3.0 \mathrm{M}$ and $1.75 \mathrm{M}$ was not very large, and sodium salicylate easily dissolved in solution I. In previous work with nitroprusside,${ }^{6} 1.4 \mathrm{M}$ salicylate, which is a little lower than that in the present work, was used. The peak height decreased with an increase in the concentration of salicylate in the regions of salicylate concentrations more than $1.4 \mathrm{M}\left(=200 \mathrm{~g} \mathrm{l}^{-1}\right)$. This is because the nitroprusside is a very effective catalyst, and the coloration reaction is finalized in a short time compared with $\mathrm{Mn}^{2+}$.

The effect of the concentrations of sodium hypochlorite in reagent solution II on the peak height was examined by varying them from $0.02 \%$ to $0.3 \%$ (active chlorine); the obtained results are shown in Fig. 4. The peak height was increased with increasing the concentrations, and approached an almost identical height when more than $0.2 \%$ of active chlorine was present; in further experiments, $0.2 \%$ was adopted. In previous work, ${ }^{6}$ the concentration of active chlorine was $0.06 \%$, which was lower than that in the present work. This is probably because the reaction with $\mathrm{Mn}^{2+}$ as a catalyst is slower than that with nitroprusside, and therefore higher concentrations of hypochlorite are better for accelerating the reaction.

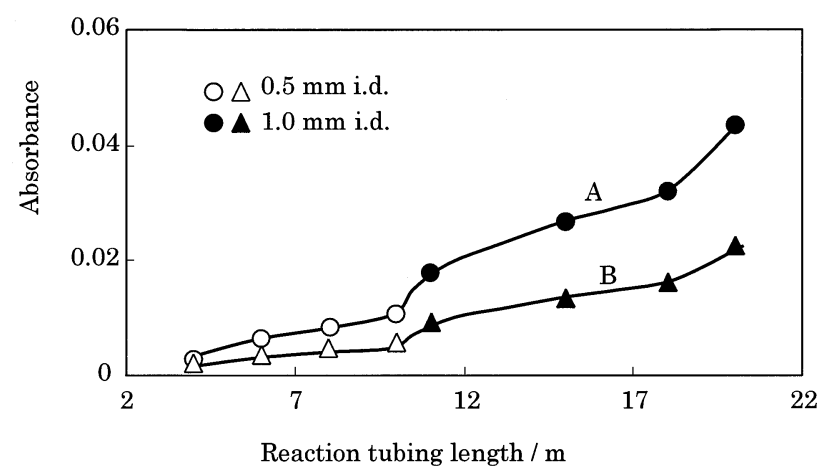

Fig. 5 Effect of the reaction tubing length on the absorbance corresponding to the peak height. $\mathrm{NH}_{4}{ }^{+}\left(\mathrm{mg} \mathrm{l}^{-1}\right)$ : (A) 5, (B) 10 . and $\triangle: 0.5 \mathrm{~mm}$ i.d. tubing; $\bullet$ and $\Delta: 1.0 \mathrm{~mm}$ i.d. tubing.

Effect of the reaction tubing length on the sensitivity improvement of ammonia detection

In previous work with nitroprusside, ${ }^{6}$ reaction tubing of 0.5 $\mathrm{mm}$ i.d. $\times 6 \mathrm{~m}$ was used; this short tubing was enough to complete the coloration reaction. However, in the present study with $\mathrm{Mn}^{2+}$ as a catalyst, the reaction rate seems to have been slower than that with nitroprusside, as shown in Fig. 2. The length of the reaction tubing was examined by varying its length (0.5 mm i.d.) from $4 \mathrm{~m}$ to $10 \mathrm{~m}$. The peak height was gradually increased with increasing the tubing length. However, the increase in the peak height was not large, as shown in Fig. 5. For a more effective enhancement of the sensitivity, a larger bore tubing (1.0 mm i.d.) was used. Tubing from $11 \mathrm{~m}$ to $20 \mathrm{~m}$ of the $1.0 \mathrm{~mm}$ i.d. was examined to make the reaction time longer. When the tubing length was increased, the peak height increased substantially (Fig. 5). When $20 \mathrm{~m}$ of $1.0 \mathrm{~mm}$ i.d. reaction tubing was used, the peak height was about 8-times higher than that of the $0.5 \mathrm{~mm}$ i.d. $\times 6 \mathrm{~m}$ used in previous work. $^{6}$ Because a high pressure was necessity to propel the solutions and a difficulty existed to use a heating apparatus for a long reaction tubing, a reaction tubing longer than $20 \mathrm{~m}$ was not examined. In further experiments, the reaction tubing was fixed at $20 \mathrm{~m} \times 1 \mathrm{~mm}$ i.d. The capacity of the $20-\mathrm{m}$ tubing corresponds to that of the $80 \mathrm{~m}$ of $0.5 \mathrm{~mm}$ i.d. in volume.

\section{Effect of the reaction temperature on the sensitivity}

The effect of the reaction temperature at the reaction tubing was examined by varying the temperature from $40^{\circ} \mathrm{C}$ to $110^{\circ} \mathrm{C}$ with an aluminum block heater. The obtained results are shown in Fig. 6. The peak height increased with an increase in the temperature, and at a temperature of $80^{\circ} \mathrm{C}$ or more the peak height became almost identical. In previous work, ${ }^{6}$ the effect of temperature on the sensitivity was very critical; the highest sensitivity was obtained at $80^{\circ} \mathrm{C}$, and at a temperature below or above $80^{\circ} \mathrm{C}$ the sensitivity became worse. In the present study, the sensitivity slightly increased up to $100^{\circ} \mathrm{C}$ and slightly decrease at $110^{\circ} \mathrm{C}$. In further experiments, the temperature was fixed at $80^{\circ} \mathrm{C}$.

\section{Effect of the sample volume and flow rate on the sensitivity}

The effect of the sample volume on the peak height was examined by varying it from $100 \mu \mathrm{l}$ to $700 \mu \mathrm{l}$. The peak height was increased with increasing the volume, and almost approached an identical height when more than $300 \mu \mathrm{l}$ was injected; in further experiments, $300 \mu \mathrm{l}$ of the sample was adopted. The effect of the flow rate of the reagent solution II containing sodium hypochlorite was examined by varying it 


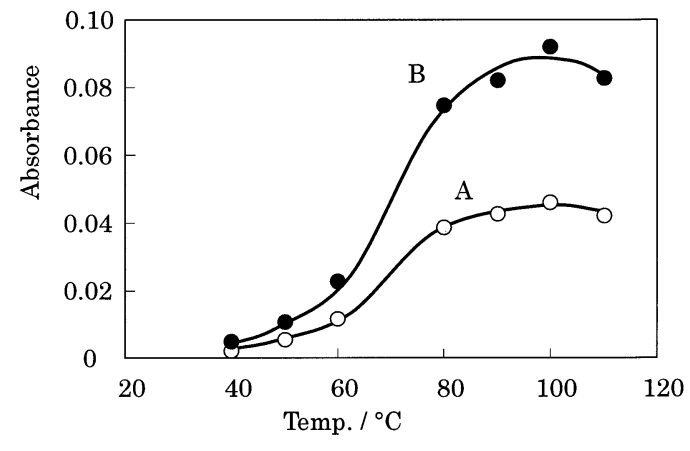

Fig. 6 Effect of the reaction temperature on the absorbance corresponding to the peak height. $\mathrm{NH}_{4}^{+}\left(\mathrm{mg} \mathrm{l}^{-1}\right)$ : (A) 0.5, (B) 1.0.

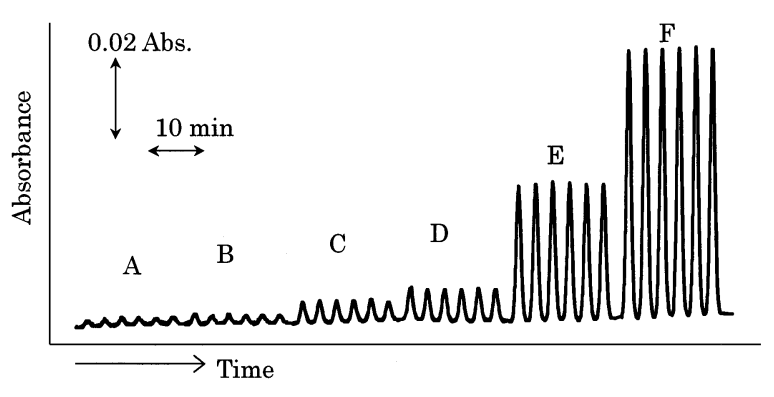

Fig. 7 Flow signals for standard ammonium ion solutions. $\mathrm{NH}_{4}{ }^{+}$ (ng ml-1): (A) 10; (B) 20; (C) 50; (D) 100; (E) 500; (F) 1000.

from 0.1 to $0.5 \mathrm{ml} \mathrm{min}^{-1}$ under the condition that the flow rate of the pump 1 was $0.5 \mathrm{ml} \mathrm{min}{ }^{-1}$. The peak height increased with increasing the flow rate, and became almost identical in the ranges between 0.2 to $0.4 \mathrm{ml} \mathrm{min}^{-1}$, and became lowered above $0.4 \mathrm{ml} \mathrm{min}^{-1}$; a flow rate of $0.2 \mathrm{ml} \mathrm{min}{ }^{-1}$ was adopted in the present study.

\section{Calibration graph}

Under the optimal conditions fixed in this work, a calibration graph for ammonia determination was prepared using the flow system shown in Fig. 1. Flow signals obtained using standard solutions of ammonium ion are shown in Fig. 7. The calibration graph showed good linearity in the range of $5-1000 \mathrm{ppb}(\mathrm{ppb} \equiv$ ng $\mathrm{ml}^{-1}$ ) of $\mathrm{NH}_{4}{ }^{+}$, and the linear-regression equation was $Y=$ $0.064 X+0.001$ (where $Y$ and $X$ represent the absorbance corresponding to peak height and the concentration ppb, respectively). The relative standard deviations for seven

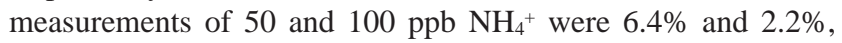
respectively. The limit of detection (LOD), corresponding to a signal-to-noise ratio of 3 , was $5 \mathrm{ppb}$ of $\mathrm{NH}_{4}{ }^{+}$. The LOD in the present study was about two-times as large as that ( $2 \mathrm{ppb})$ in the previous work with nitroprusside as a catalyst, ${ }^{6}$ and almost the same as that in the long gas-diffusion/FIA method. ${ }^{7}$ The time required to measure one sample by the proposed FIA method was about $3 \mathrm{~min}$, which was much shorter compared with the conventional method now used in the JIS method. ${ }^{1}$

\section{Effect of coexisting ions}

The interferences due to various ions usually found in a absorption liquid, which absorbs ammonia in the boiler exhaust gas, were examined. The obtained results are given in Table 2 . The concentrations of the various ions in the solutions that absorbed actual exhaust gas were fairly lower than those in Table 2. As a result, the interferences from coexisting ions are not necessary to take into account in the proposed method.
Table 2 Effects of coexisting substances that can exist in the absorption liquid for the usual boiler exhaust gas

\begin{tabular}{lc}
\hline \multicolumn{1}{c}{ Substance } & Tolerable concentrations of ion/M \\
\hline $\mathrm{Na}^{+}, \mathrm{Cl}^{-}$ & $1.0 \times 10^{-4}$ \\
$\mathrm{Ca}^{2+}, \mathrm{K}^{+}, \mathrm{Mg}^{2+}, \mathrm{CO}_{3}^{2-}, \mathrm{SO}_{4}^{2-}$ & $0.5 \times 10^{-3}$ \\
$\mathrm{NO}_{3}^{-}, \mathrm{NO}_{2}^{-}, \mathrm{Si}^{2+}, \mathrm{Al}^{2+}, \mathrm{Fe}^{2+}$ & $1.0 \times 10^{-3}$ \\
\hline
\end{tabular}

Table 3 Determination of ammonium ion in absorption liquids which dissolved ammonia in real boiler exhaust gas

\begin{tabular}{ccccccc}
\hline & \multicolumn{3}{c}{ This method } & \multicolumn{3}{c}{ Ion chromatog $^{\mathrm{c}}(n=3)$} \\
Sample & $\begin{array}{c}\mathrm{NH}_{4}{ }^{\mathrm{a} /} \\
\mathrm{mg} \mathrm{l}^{-1}\end{array}$ & $\begin{array}{c}\mathrm{RSD}^{\mathrm{b}}, \\
\%\end{array}$ & $\begin{array}{c}\mathrm{NH}_{3}{ }^{\mathrm{d}}, \\
\mathrm{ppm}\end{array}$ & $\begin{array}{c}\mathrm{NH}_{4}{ }^{+} / \\
\mathrm{mg} \mathrm{l}^{-1}\end{array}$ & $\begin{array}{c}\mathrm{RSD}, \\
\%\end{array}$ & $\begin{array}{c}\mathrm{NH}_{3}{ }^{\mathrm{d}}, \\
\mathrm{ppm}\end{array}$ \\
\hline $\mathrm{A}$ & 0.54 & 2.2 & 18.2 & 0.54 & 1.1 & 18.2 \\
$\mathrm{~B}$ & 1.03 & 1.8 & 34.8 & 1.00 & 0.8 & 33.8 \\
\hline
\end{tabular}

a. Mean values of six measurements. b. Relative standard deviations of six measurements. c. Exhaust gas sampled was 10 1, which was absorbed in $250 \mathrm{ml}$ of the absorption liquid (boric acid solution) by using the gas sampling system. d. Ammonia contents in exhaust gas: $\mathrm{ppm}(\mathrm{v} / \mathrm{v})$.

Application to the determination of ammonium ion in practical samples

The determination of ammonium ion in the absorption liquids was performed by the proposed method. The concentrations of ammonium ion in the absorption liquids determined by the proposed method are summarized in Table 3. The analytical results obtained by the proposed method are in good agreement with those obtained by ion chromatography. From these results, the proposed method was found to be sufficiently sensitive for the determination of ammonia for contents of $0.6 \mathrm{ppm}$ ( $\mathrm{ppm} \equiv 1$ $\mathrm{ml} \mathrm{m}^{-3}$ ) or more in the exhaust gas, when ammonia in $10 \mathrm{lof}$ exhaust gas was absorbed in $250 \mathrm{ml}$ of the absorption liquid using the ammonia sampling system, which has already been developed and used in our thermal power plant.

The proposed method does not require a highly toxic substance, like nitroprusside. Furthermore, there are some advantages in the proposed FIA method: a shortening of the measurement time, a simple and automatical measurement procedure, and a relatively sensitive method for the determination of ammonia. Also, the proposed method can be widely applicable to various kinds of practical samples, for example river, lake and sea water samples.

\section{References}

1. JIS 0099, "Methods for Determination of Ammonia in Exhaust Gas", 1983, Japanese Industrial Standards Committee, Tokyo.

2. T. Kuroishi and N. Iwamura, J. Flow Injection Anal., 2000, 16 (Supplement), 44.

3. APHA-AWWA.WEF, "Standard Methods for the Examination of Water and Wastewater", 20th ed., 1998, American Public Health Association, Washington, D.C., 4 - 111.

4. K. Higuchi and Y. Ogawa, J. Flow Injection Anal., 2000, 16 (Supplement), 48.

5. H. Muraki, K. Higuchi, M. Sasaki, T. Korenaga, and K. Tôei, Anal. Chim. Acta, 1992, 261, 345.

6. T. Tsuboi, Y. Hirano, M. Oshima, and S. Motomizu, J. Flow Injection Anal., 2000, 17, 77.

7. T. Tsuboi, Y. Hirano, Y. Shibata, and S. Motomizu, Bunseki Kagaku, 2002, 51, 47. 